Published in final edited form as:

Am J Perinatol. 2014 October ; 31(9): 811-822. doi:10.1055/s-0033-1361933.

\title{
Medication use in the neonatal intensive care unit
}

\author{
Emily M. Hsieh, MD ${ }^{1,2}$, Christoph P. Hornik, MD, MPH ${ }^{2,3}$, Reese H. Clark, MD4, Matthew M. \\ Laughon, $\mathbf{M D}^{5}$, Daniel K. Benjamin Jr., MD, PhD, MPH ${ }^{2,3}$, and P. Brian Smith, MD, MPH, \\ MHS $^{2,3}$ on behalf of the Best Pharmaceuticals for Children Act - Pediatric Trials Network \\ Emily M. Hsieh: emily.m.hsieh@gmail.com; Christoph P. Hornik: christoph.hornik@dm.duke.edu; Reese H. Clark: \\ Reese_Clark@pediatrix.com; Matthew M. Laughon: matt_laughon@med.unc.edu; Daniel K. Benjamin: \\ danny.benjamin@dm.duke.edu; P. Brian Smith: Brian.Smith@dm.duke.edu \\ ${ }^{1}$ Duke-National University of Singapore Graduate Medical School, Singapore \\ ${ }^{2}$ Duke Clinical Research Institute, Durham, North Carolina, USA \\ ${ }^{3}$ Department of Pediatrics, Duke University, Durham, North Carolina, USA \\ ${ }^{4}$ Pediatrix-Obstetrix Center for Research and Education, Sunrise, Florida, USA \\ ${ }^{5}$ Department of Pediatrics, University of North Carolina, Chapel Hill, North Carolina, USA
}

\section{Abstract}

Objective-We provide an update on medication use in infants admitted to the neonatal intensive care unit (NICU) in the United States and examine how use has changed over time.

Study Design-We performed a retrospective review (2005-2010) of a large prospectively collected administrative database.

Result-Medications most commonly administered during the study period were ampicillin, gentamicin, caffeine citrate, vancomycin, beractant, furosemide, fentanyl, dopamine, midazolam, and calfactant (56-681 exposures per 1000 infants). Those with the greatest relative increase in use included azithromycin, sildenafil, and milrinone. Medications with the greatest relative decrease in use included theophylline, metoclopramide, and doxapram.

Conclusion-Medication use in the NICU has changed substantially over time, and only $35 \%$ of the most commonly prescribed medications are FDA-approved in infants.

\section{Keywords}

pharmacotherapy; trends over time

\section{Introduction}

Infants in the neonatal intensive care unit (NICU) are exposed to a large number of medications, most of which are not labeled for use in infants because clinical trials for

\footnotetext{
Address for correspondence: P. Brian Smith, MD, MPH, MHS, Duke Clinical Research Institute, Box 17969, Durham, NC, 27715; phone: 919-668-8951; fax: 919-668-7058; brian.smith@duke.edu.

Conflicts of interest

Drs. Hsieh, Hornik, and Clark have nothing to disclose.
} 
safety, dosing, and efficacy of drugs are lacking in this population. ${ }^{1}$ Hospitalized infants are often excluded from clinical trials due to ethical concerns and difficulties with recruitment. ${ }^{2}$ Furthermore, these hospitalized infants in the NICU are more likely to be pre-term, with greater proportions exhibiting renal and hepatic dysfunction. These characteristics are often exclusion criteria for many clinical trials. As a result, clinicians are forced to prescribe medications for purposes outside of their licensed indications (i.e., off-label use). ${ }^{3-5}$

Previous investigators described medication use in the NICU through $2005 .{ }^{6}$ However, clinical practice and prescribing patterns change over time as clinical trial data and new Food and Drug Administration (FDA) labeling information become available. The aims of this study were (1) to provide the most recent description of current prescribing practices in the NICU and (2) to examine changes in prescribing practices over time.

\section{Methods}

\section{Study population}

We obtained demographic, outcome, and medication administration data from infants discharged from 305 NICUs managed by the Pediatrix Medical Group from 2005-2010. Data were obtained from an administrative database that prospectively captures information from daily progress notes generated by clinicians using a computer-assisted tool on all infants cared for by the Pediatrix Medical Group. Information is collected regarding maternal history and demographics, physical exam findings, medications, laboratory results, culture results, diagnoses, and other aspects of clinical care. We excluded infants admitted after day of life 120, and all vitamins (except vitamin A), nutritional supplements, vaccines, eye drops, and topical medications.

\section{Definitions}

We used counts and proportions to describe medication use by 3 different methods. Total medication courses (frequency or raw count) represented the number of times a unique medication name was reported in the database. Exposure was defined as the number of unique medication names that were reported for each patient. Days of use was defined as the total number of days each medication was administered in the entire database. For example, if a medication was prescribed to 2 patients once and to 1 patient twice for a duration of 2 days each time, the medication would be reported as: exposure $=1+1+1=3$; course $=1+1+2=4$; days $=(1 * 2)+(1 * 2)+(2 * 2)=8$. In addition, medication exposures in extremely low birth weight (ELBW, $<1000 \mathrm{~g}$ birth weight) infants and in infants who died prior to NICU discharge were determined.

The change in frequency of medication administration between 2005 and 2010 was described by both absolute and relative change. Relative increases in medication use were limited to medications with $\geq 1 / 1000$ infant exposures in 2005, and relative decreases in medication use were limited to medication with $\geq 1 / 1000$ infant exposures in 2010. We conducted the analysis using STATA 12 (College Station, TX). This study was approved by the Duke Institutional Review Board. 


\section{Results}

\section{Study population and counting method}

A total of 450,386 infants were discharged during the study period, and 29,336 (6.5\%) were ELBW infants. The median birth weight of the study population was $2490 \mathrm{~g}\left(25^{\text {th }}, 75^{\text {th }}\right.$ percentile: 1830,3191$)$, and the median gestational age was 35 weeks $(33,38)$. The median length of hospitalization was 10 days $(5,21)$, and $56 \%$ of the infants were male. Overall mortality was $2.4 \%$, which was similar to the previous study $(2.7 \%)$.

We identified 1,655,397 unique medication courses for 229 medications. The mean number of medication courses per infant was $4(1,14)$ for the entire cohort and $17(2,45)$ for ELBW infants. There were minimal differences in the rankings of medications when calculated by the 3 methods. Therefore, only exposures were reported for Tables 2 through 6 . The 10 most commonly reported medications, by exposure, in the NICU were ampicillin, gentamicin, caffeine citrate, vancomycin, beractant, furosemide, fentanyl, dopamine, midazolam, and calfactant (Table 1). For ELBW infants, the 10 most commonly reported medications by exposure were gentamicin, ampicillin, caffeine citrate, vancomycin, furosemide, dopamine, beractant, indomethacin, fentanyl, and albuterol (Table 2). FDA approval status for the medications most commonly used in the ELBW population is also shown in Table 2.

\section{Medication use between 2005 and 2010}

Drugs with the greatest relative increase in medication exposure from 2005 to 2010 included azithromycin, sildenafil, milrinone, ibuprofen, linezolid, cefoxitin, methadone, vitamin A, hyaluronidase, and poractant alpha (Table 3). Those with the greatest absolute increase in medication exposure from 2005 to 2010 included poractant alpha, vitamin A, ibuprofen, fluconazole, piperacillin/tazobactam, lansoprazole, methadone, morphine, meropenem, and nitric oxide (Table 4). Medications appearing on both lists included ibuprofen, methadone, and vitamin A.

\section{Medication decreases between 2005 and 2010}

Drugs with the greatest relative decrease in medication exposure from 2005 to 2010 included theophylline, metoclopramide, doxapram, aminophylline, epoietin alpha, imipenem +cilastatin, ranitidine, sodium polystyrene sulfonate, and bethanechol (Table 5). Those with the greatest absolute decrease in medication exposure from 2005 to 2010 included metoclopramide, ranitidine, ampicillin, cefotaxime, indomethacin, epoietin alpha, beractant, gentamicin, dopamine, and calfactant (Table 6). Medication use in ELBW infants is shown in Tables 7-10.

\section{Discussion}

Of the most commonly reported medications identified in our study, only $35 \%$ are FDAapproved in the newborn. From 1997-2010, 28 drugs had 24 FDA labeling changes in neonates. Only 2, famotidine and linezolid, were among the top 100 medications (\#62 and $\# 100$, respectively). Such off-label drug use is concerning because, frequently, little is known about the drugs' potential side effects and adverse events; furthermore, dangerous 
errors may be made in adjusting adult doses and formulations for infants and children. In fact, off-label drug use is associated with increased adverse drug reactions, ${ }^{7}$ and the incidence of death and injury associated with adverse drug events in infants and children is likely substantially higher than what is actually reported. ${ }^{8}$

Several factors may have influenced the changes in medication use observed over time. An increasing number of studies investigating safety and pharmacokinetic properties of specific molecules have led to a better understanding of their effects in the target population. For example, emerging evidence has demonstrated the effectiveness of fluconazole prophylaxis in preventing invasive Candida infection in ELBW infants at high risk of invasive candidiasis. ${ }^{9-11}$ In addition, the dosing of fluconazole has been described for both treatment and prophylaxis. ${ }^{12}$ This increased understanding of the dosing, safety, and efficacy around fluconazole use likely accounts for the increase in its use (ranked $4^{\text {th }}$ in absolute increase and $18^{\text {th }}$ in relative increase).

On the other hand, little evidence exists for the efficacy of metoclopramide use for gastroesophageal reflux disease (GERD) in infants, which showed the second largest relative decrease in use between 2005 and 2010. A 2006 systematic literature review of metoclopramide for GERD in infants aged 0 to 23 months identified 4 studies that reported adverse effects of therapy, including irritability, dystonic reactions, drowsiness, oculogyric crisis, emesis, and apnea. ${ }^{13}$ In 2009, the FDA required manufacturers to add a box warning to their drug labels about the risk of metoclopramide's long-term or high-dose use: chronic use of metoclopramide has been linked to tardive dyskinesia even after therapy has been discontinued. ${ }^{14}$ During the time period of our study, Pediatrix Medical Group implemented a new electronic module dedicated to clinical quality improvement initiatives, ${ }^{15}$ the success of which can be observed with the decrease in anti-reflux medication use. ${ }^{16}$ Even with the decrease in metoclopramide use, however, metoclopramide was one top 20 most commonly used medications in the NICU.

Similarly, although ranitidine remained in the top 15 most commonly used medications in both the NICU, it experienced the second largest absolute decrease in medication use from 2005 to 2010. During this time, data were published linking the use of $\mathrm{H} 2$ blockers to necrotizing enterocolitis (NEC) in very low birth weight $(<1500 \mathrm{~g}$ birth weight) infants $($ odds ratio $=1.71[95 \%$ confidence interval: $1.34-2.19]) .{ }^{17}$

In addition, medications that have increased in use may have their own risks and adverse effects. There has been a decrease in third-generation cephalosporin use after their use was associated with increased risk of Candida infections. ${ }^{18}$ This decrease corresponded with an increased use of piperacillin-tazobactam (ranked $5^{\text {th }}$ in absolute increase and $14^{\text {th }}$ in relative increase) and meropenem (ranked $9^{\text {th }}$ in absolute increase and $13^{\text {th }}$ in relative increase). These agents may carry similar risks given their broad spectrum of antimicrobial activity.

The introduction of newer and potentially safer medications may also drive changes in medication use. For example, indomethacin has been the conventional treatment for patent ductus arteriosus (PDA) in premature infants. In April 2006, the FDA approved ibuprofen lysine for closure of clinically significant PDA in premature infants because studies have 
shown ibuprofen to be safer and equally as effective as indomethacin. ${ }^{19}$ Subsequently, there has been a rise in the use of ibuprofen ( $3^{\text {rd }}$ largest absolute increase in medication use) and a fall in indomethacin use ( $5^{\text {th }}$ largest absolute decrease in medication use). However, in spite of these changes in prescribing patterns, indomethacin is still a commonly used medication in the ELBW infants (ranked $8^{\text {th }}$ ).

One of the most common complications of premature birth is bronchopulmonary dysplasia (BPD) ${ }^{20}$ and up to $20 \%$ of infants with BPD develop pulmonary hypertension. As a result, sildenafil, approved for pulmonary hypertension in adults, has increased in use since 2005 $\left(2^{\text {nd }}\right.$ greatest relative increase). However, the FDA recently recommended against the use of sildenafil in children ages 1 though 17 for the treatment of pulmonary arterial hypertension. This recommendation was based on a recent long-term pediatric clinical trial showing that children taking a high dose of sildenafil had a higher risk of death when compared to children taking a low dose, and that the low dose of sildenafil was not effective in improving exercise ability. ${ }^{21}$

The strengths of our study include the use of a large, representative cohort, as well as daily documentation of medication prescriptions for infants in the NICU. Our study is limited by the use of administrative data for the analysis. These data are not from a prospective clinical trial that has undergone the scrutiny of independent monitoring, but rather are derived from prospectively collected electronic documentation.

In summary, we identified the most commonly reported medications used in the NICU and how medication use has changed over time. Frequent studies of medication use patterns should be conducted to facilitate optimal prioritization of drug studies in infants. As many of the drugs used in the NICU are used off-label and have not been adequately studied in this population, these data are useful for researchers and NIH in setting research priorities.

\section{Acknowledgments}

This work was funded under NICHD contract HHSN2752010000031 for the Pediatric Trials Network. The NICHD played no role in the design and conduct of the study; collection, management, analysis, and interpretation of the data; or preparation, review, or approval of the manuscript. P. Brian Smith had full access to all of the data in the study and takes responsibility for the integrity of the data and the accuracy of the data analysis.

Dr. Benjamin receives support from the United States government for his work in pediatric and neonatal clinical pharmacology (1R01HD057956-05, 1K24HD058735-05, and NICHD contract HHSN275201000003I) and the nonprofit organization Thrasher Research Fund for his work in neonatal candidiasis (www.thrasherresearch.org); he also receives research support from industry for neonatal and pediatric drug development (www.dcri.duke.edu/ research/coi.jsp). Dr. Smith receives support for research from the National Institutes of Health and the U.S. Department of Health and Human Services (NICHD 1K23HD060040-01, DHHS-1R18AE000028-01, and HHSN267200700051C); he also receives research support from industry for neonatal and pediatric drug development (www.dcri.duke.edu/research/coi.jsp). Dr. Laughon receives support from the U.S. government for his work in pediatric and neonatal clinical pharmacology (Government Contract HHSN267200700051C, PI: Benjamin, under the Best Pharmaceuticals for Children Act) and from NICHD 1K23HL092225-01.

\section{References}

1. Barr J, Brenner-Zada G, Heiman E, et al. Unlicensed and off-label medication use in a neonatal intensive care unit: a prospective study. Am J Perinatol. 2002; 19:67-72. [PubMed: 11938479]

2. Bavdekar S, Gogtay N. Unlicensed and off-label drug use in children. J Postgrad Med. 2005; 51:249-252. [PubMed: 16388164] 
3. Pandolfini C, Bonati M. A literature review on off-label drug use in children. Eur J Pediatr. 2005; 164:552-558. [PubMed: 15912383]

4. Cuzzolin L, Atzei A, Fanos V. Off-label and unlicensed prescribing for newborns and children in different settings: a review of the literature and a consideration about drug safety. Expert Opin Drug Saf. 2006; 5:703-718. [PubMed: 16907660]

5. Conroy S, McIntyre J. The use of unlicensed and off-label medicines in the neonate. Semin Fetal Neonatal Med. 2005; 10:115-122. [PubMed: 15701577]

6. Clark RH, Bloom B, Spitzer A, Gerstman D. Reported medication use in the neonatal intensive care unit: data from a large national data set. Pediatrics. 2006; 117:1979-1987. [PubMed: 16740839]

7. Horen B, Montastruc J-L, Lapeyre-Mestre M. Adverse drug reactions and off-label drug use in pediatric outpatients. Br J Clin Pharmacol. 2002; 54:665-670. [PubMed: 12492616]

8. Moore TJ, Weiss SR, Kaplan S, Blaisdell CJ. Reported adverse drug events in infants and children under 2 years of age. Pediatrics. 2002; 110:5.

9. Kaufman D, Boyle R, Hazen KC, Patrie JT, Robinson M, Grossman LB. Twice weekly fluconazole prophylaxis for prevention of invasive Candida infection in high-risk infants of $<1000$ grams birth weight. J Pediatr. 2005; 147:172-179. [PubMed: 16126045]

10. Manzoni P, Stolfi I, Pugni L, et al. Italian Task Force for the Study and Prevention of Neonatal Fungal Infections; Italian Society of Neonatology. A multicenter, randomized trial of prophylactic fluconazole in preterm neonates. N Engl J Med. 2007; 356:2483-2495. [PubMed: 17568029]

11. Kaufman DA, Manzoni P. Strategies to prevent invasive candidal infection in extremely preterm infants. Clin Perinatol. 2010; 37:611-628. [PubMed: 20813274]

12. Wade KC, Wu D, Kaufman DA, et al. National Institute of Child Health and Development Pediatric Pharmacology Research Unit Network. Population phamacokinetics of fluconazole in young infants. Antimicrob Agents Chemother. 2008; 52:4043-4049. [PubMed: 18809946]

13. Hibbs AM, Lorch SA. Metoclopramide for the treatment of gastroesophageal reflux disease in infants: a systematic review. Pediatrics. 2006; 118:746-752. [PubMed: 16882832]

14. U.S. Food and Drug Administration. [Accessed July 6, 2012] Reglan (metoclopramide) tablets, ODT (orally disintegrating tablets), and injection. Available at: http://www.fda.gov/Safety/ MedWatch/SafetyInformation/ucm170934.htm

15. Spitzer AR, Ellsbury DL, Handler D, Clark RH. The Pediatrix BabySteps Data Warehouse and the Pediatrix QualitySteps improvement project system - tools for "meaningful use" in continuous quality improvement. Clin Perinatol. 2010; 37:49-70. [PubMed: 20363447]

16. Clark RH, Sptizer AR. Patience is a virtue in the managament of gastroesophageal reflux. $\mathbf{J}$ Pediatr. 2009; 155:464-465. [PubMed: 19772996]

17. Guillet R, Stoll BJ, Cotten CM, et al. National Institute of Child Health and Human Development Neonatal Research Network. Association of H2-blocker therapy and higher incidence of necrotizing enterocolitis in very low birth weight infants. Pediatrics. 2006; 117:e137-e142. [PubMed: 16390920]

18. Benjamin DK Jr, Stoll BJ, Fanaroff AA, et al. National Institute of Child Health and Human Development Neonatal Research Network. Neonatal candidiasis among extremely low birth weight infants: risk factors, mortality rates, and neurodevelopmental outcomes at 18 to 22 months. Pediatrics. 2006; 117:84-92. [PubMed: 16396864]

19. Van Overmeire B, Smets K, Lecoutere D, et al. A comparison of ibuprofen and indomethacin for closure of patent ductus arteriosus. N Engl J Med. 2000; 343:674-681. [PubMed: 10974130]

20. Greenough A. Long term respiratory outcomes of very premature birth (<32 weeks). Semin Fetal Neonatal Med. 2012; 17:73-76. [PubMed: 22300711]

21. Barst RJ, Ivy DD, Gaitan G, et al. A randomized, double-blind, placebo-controlled, dose-ranging study of oral sildenafil citrate in treatment-naive children with pulmonary arterial hypertension. Circulation. 2012; 125:324-334. [PubMed: 22128226] 


\section{The PTN Administrative Core Committee}

Daniel K. Benjamin Jr., Duke Clinical Research Institute, Durham, NC; Katherine Berezny, Duke Clinical Research Institute, Durham, NC; Jeffrey Barrett, Children's Hospital of Philadelphia, Philadelphia, PA; Edmund Capparelli, University of California-San Diego, San Diego, CA; Michael Cohen-Wolkowiez, Duke Clinical Research Institute, Durham, NC; Gregory L. Kearns, Children's Mercy Hospital, Kansas City, MO; Matthew Laughon, University of North Carolina at Chapel Hill, Chapel Hill, NC; Andre Muelenaer, Virginia Tech Carilion School of Medicine, Roanoke, VA; T. Michael O'Shea, Wake Forest Baptist Medical Center, Winston Salem, NC; Ian M. Paul, Penn State College of Medicine, Hershey, PA; P. Brian Smith, Duke Clinical Research Institute Durham, NC; John van den Anker, George Washington University School of Medicine and Health, Washington, DC; Kelly Wade, Children's Hospital of Philadelphia, Philadelphia, PA

The Eunice Kennedy Shriver National Institute of Child Health and Human Development: David Siegel, Perdita Taylor-Zapata, Anne Zajicek, Katerina Tsilou, Alice Pagan

The EMMES Corporation (Data Coordinating Center): Ravinder Anand, Diane Brandt, Traci Clemons, Gina Simone 


\section{Table 1}

Medications most commonly used in the NICU

\begin{tabular}{|c|c|c|c|c|}
\hline Rank & Medication & Exposure* & Courses* & Days of use * \\
\hline 1 & Ampicillin & 681 & 709 & 3069 \\
\hline 2 & Gentamicin & 676 & 785 & 3521 \\
\hline 3 & Caffeine citrate & 156 & 199 & 3908 \\
\hline 4 & Vancomycin & 91 & 150 & 987 \\
\hline 5 & Beractant & 82 & 91 & 103 \\
\hline 6 & Furosemide & 81 & 171 & 668 \\
\hline 7 & Fentanyl & 70 & 86 & 677 \\
\hline 8 & Dopamine & 62 & 77 & 327 \\
\hline 9 & Midazolam & 61 & 71 & 679 \\
\hline 10 & Calfactant & 56 & 66 & 72 \\
\hline 11 & Metoclopramide & 54 & 63 & 706 \\
\hline 12 & Ranitidine & 52 & 62 & 591 \\
\hline 13 & Poractant alpha & 51 & 56 & 61 \\
\hline 14 & Morphine & 51 & 62 & 527 \\
\hline 15 & Cefotaxime & 43 & 53 & 316 \\
\hline 16 & Acetaminophen & 43 & 48 & 241 \\
\hline 17 & Indomethacin & 39 & 50 & 121 \\
\hline 18 & Phenobarbital & 38 & 48 & 427 \\
\hline 19 & Albuterol & 27 & 35 & 611 \\
\hline 20 & Epoietin alpha & 26 & 30 & 631 \\
\hline 21 & Lorazepam & 25 & 28 & 290 \\
\hline 22 & Hydrocortisone & 25 & 32 & 290 \\
\hline 23 & Tobramycin & 24 & 34 & 189 \\
\hline 24 & Erythromycin & 24 & 25 & 103 \\
\hline 25 & Dobutamine & 20 & 23 & 78 \\
\hline 26 & Dexamethasone & 20 & 30 & 159 \\
\hline 27 & Fluconazole & 19 & 23 & 321 \\
\hline 28 & Clindamycin & 17 & 19 & 128 \\
\hline 29 & Palivizumab & 17 & 17 & 24 \\
\hline 30 & Acyclovir & 16 & 16 & 82 \\
\hline 31 & Vitamin A & 15 & 15 & 363 \\
\hline 32 & Insulin & 14 & 17 & 73 \\
\hline 33 & Ursodeoxycholic acid & 14 & 18 & 259 \\
\hline 34 & Lansoprazole & 14 & 15 & 106 \\
\hline 35 & Spironolactone & 14 & 17 & 251 \\
\hline 36 & Chlorothiazide & 12 & 16 & 230 \\
\hline
\end{tabular}




\begin{tabular}{|c|c|c|c|c|}
\hline Rank & Medication & Exposure ${ }^{*}$ & Courses* & Days of use \\
\hline 37 & Aminophylline & 12 & 13 & 165 \\
\hline 38 & Ceftazidime & 12 & 15 & 99 \\
\hline 39 & Alprostadil & 12 & 12 & 22 \\
\hline 40 & Nitric oxide & 11 & 12 & 82 \\
\hline 41 & Piperacillin/tazobactam & 11 & 15 & 115 \\
\hline 42 & Epinephrine & 11 & 12 & 25 \\
\hline 43 & Amoxicillin & 11 & 12 & 72 \\
\hline 44 & Metronidazole & 11 & 13 & 97 \\
\hline 45 & Oxacillin & 10 & 14 & 67 \\
\hline 46 & Nafcillin & 9.0 & 11 & 66 \\
\hline 47 & Amphotericin B products & 8.9 & 11 & 99 \\
\hline 48 & Amikacin & 8.8 & 12 & 77 \\
\hline 49 & Vecuronium & 8.5 & 9.8 & 33 \\
\hline 50 & Ibuprofen & 8.3 & 11 & 35 \\
\hline 51 & Cefazolin & 7.5 & 8.1 & 27 \\
\hline 52 & Meropenem & 7.0 & 8.9 & 82 \\
\hline 53 & Simethicone & 6.9 & 7.2 & 59 \\
\hline 54 & Levothyroxine & 6.7 & 7.2 & 157 \\
\hline 55 & Fluticasone & 6.7 & 8.1 & 170 \\
\hline 56 & Budesonide & 6.6 & 7.6 & 153 \\
\hline 57 & Phenylephrine & 6.6 & 7.3 & 29 \\
\hline 58 & Omeprazole & 6.5 & 7.0 & 64 \\
\hline 59 & Epinephrine racemic & 6.3 & 7.4 & 20 \\
\hline 60 & Cefepime & 6.1 & 7.7 & 58 \\
\hline 61 & Pancuronium & 6.1 & 6.8 & 22 \\
\hline 62 & Famotidine & 5.3 & 6.2 & 62 \\
\hline 63 & Methadone & 5.2 & 6.1 & 86 \\
\hline 64 & Digoxin & 5.1 & 5.7 & 28 \\
\hline 65 & Chloral hydrate & 5.0 & 5.5 & 28 \\
\hline 66 & Penicillin G & 4.7 & 4.9 & 38 \\
\hline 67 & Naloxone & 4.3 & 4.4 & 4.7 \\
\hline 68 & Pentobarbital & 4.3 & 4.7 & 49 \\
\hline 69 & Prednisone/prednisolone & 4.2 & 5.2 & 47 \\
\hline 70 & Aluminum/magnesium hydroxide & 4.2 & 4.7 & 27 \\
\hline 71 & Theophylline & 4.1 & 5.0 & 102 \\
\hline 72 & Filgrastim & 3.8 & 4.4 & 13 \\
\hline 73 & Hydrochlorothiazide & 3.7 & 4.5 & 61 \\
\hline 74 & Rifampin & 3.6 & 3.8 & 36 \\
\hline 75 & Propranolol & 3.4 & 3.7 & 15 \\
\hline
\end{tabular}




\begin{tabular}{|c|c|c|c|c|}
\hline Rank & Medication & Exposure* & Courses* & Days of use \\
\hline 76 & THAM acetate & 3.1 & 4.0 & 5.2 \\
\hline 77 & Imipenem+cilastatin & 3.0 & 3.3 & 29 \\
\hline 78 & Milrinone & 2.9 & 3.0 & 15 \\
\hline 79 & Hyaluronidase & 2.8 & 2.9 & 3.1 \\
\hline 80 & Bumetanide & 2.8 & 3.8 & 26 \\
\hline 81 & Hydralazine & 2.5 & 2.8 & 28 \\
\hline 82 & Surfactant (unknown type) & 2.4 & 2.6 & 3.9 \\
\hline 83 & Captopril & 2.3 & 2.6 & 24 \\
\hline 84 & Beclomethasone & 2.1 & 2.8 & 32 \\
\hline 85 & Adenosine & 2.1 & 2.5 & 4.0 \\
\hline 86 & Acetazolamide & 2.1 & 3.7 & 24 \\
\hline 87 & Sodium polystyrene sulfonate & 2.1 & 2.3 & 5.3 \\
\hline 88 & Diazepam & 2.0 & 2.4 & 28 \\
\hline 89 & Zidovudine & 1.9 & 2.0 & 15 \\
\hline 90 & Cephalexin & 1.9 & 2.0 & 9.5 \\
\hline 91 & Ceftriaxone & 1.8 & 1.8 & 5.7 \\
\hline 92 & Ipratropium & 1.7 & 1.9 & 42 \\
\hline 93 & Dornase Alpha & 1.6 & 2.2 & 16 \\
\hline 94 & Sulfamethoxazole+trimethoprim & 1.6 & 1.8 & 16 \\
\hline 95 & Enalapril & 1.5 & 1.8 & 13 \\
\hline 96 & Cefoxitin & 1.5 & 1.6 & 4.9 \\
\hline 97 & Doxapram & 1.4 & 2.0 & 25 \\
\hline 98 & Fosphenytoin & 1.4 & 1.6 & 10 \\
\hline 99 & Sildenafil & 1.4 & 1.6 & 27 \\
\hline 100 & Linezolid & 1.3 & 1.6 & 14 \\
\hline
\end{tabular}




\section{Table 2}

Medications most commonly used in extremely low birth weight infants

\begin{tabular}{|c|c|c|c|}
\hline Rank & Medication & Exposure* $^{*}$ & FDA-approved in ELBW infants \\
\hline 1 & Gentamicin & 896 & Yes \\
\hline 2 & Ampicillin & 881 & No \\
\hline 3 & Caffeine citrate & 704 & No \\
\hline 4 & Vancomycin & 559 & Yes \\
\hline 5 & Furosemide & 495 & No \\
\hline 6 & Dopamine & 425 & No \\
\hline 7 & Beractant & 339 & Yes \\
\hline 8 & Indomethacin & 334 & Yes \\
\hline 9 & Fentanyl & 322 & No \\
\hline 10 & Albuterol & 241 & No \\
\hline 11 & Calfactant & 240 & Yes \\
\hline 12 & Midazolam & 236 & Yes \\
\hline 13 & Hydrocortisone & 215 & No \\
\hline 14 & Cefotaxime & 214 & Yes \\
\hline 15 & Ranitidine & 212 & No \\
\hline 16 & Metoclopramide & 195 & No \\
\hline 17 & Morphine & 194 & No \\
\hline 18 & Fluconazole & 191 & No \\
\hline 19 & Dexamethasone & 176 & No \\
\hline 20 & Vitamin A & 174 & No \\
\hline
\end{tabular}


Table 3

Greatest relative increase in exposure between 2005 and 2010 ( $\geq 1 / 1000$ infant exposures in 2010)

\begin{tabular}{|c|c|c|c|c|}
\hline Rank & Medication & $\%$ Change & Exposure $(2005)^{*}$ & Exposure (2010) \\
\hline 1 & Azithromycin & 2900 & 0.1 & 3.0 \\
\hline 2 & Sildenafil & 1050 & 0.2 & 2.3 \\
\hline 3 & Milrinone & 900 & 0.4 & 4.0 \\
\hline 4 & Ibuprofen & 650 & 1.4 & 11 \\
\hline 5 & Linezolid & 500 & 0.4 & 2.4 \\
\hline 6 & Cefoxitin & 350 & 0.4 & 1.8 \\
\hline 7 & Methadone & 158 & 3.1 & 8.0 \\
\hline 8 & Vitamin A & 152 & 8.3 & 21 \\
\hline 9 & Hyaluronidase & 107 & 1.5 & 3.1 \\
\hline 10 & Poractant alpha & 101 & 32 & 63 \\
\hline 11 & Meropenem & 100 & 4.5 & 9.0 \\
\hline 12 & Piperacillin/tazobactam & 97 & 6.2 & 12 \\
\hline 13 & Cefepime & 70 & 4.6 & 7.8 \\
\hline 14 & Famotidine & 60 & 4.7 & 7.5 \\
\hline 15 & Lansoprazole & 58 & 9.8 & 16 \\
\hline 16 & Fluconazole & 44 & 14 & 21 \\
\hline 17 & Diazepam & 44 & 1.6 & 2.3 \\
\hline 18 & Nitric oxide & 42 & 8.9 & 13 \\
\hline 19 & Cefazolin & 38 & 6.3 & 8.7 \\
\hline 20 & Prednisone/Prednisolone & 36 & 3.9 & 5.3 \\
\hline
\end{tabular}


Table 4

Greatest absolute increase in exposure between 2005 and 2010

\begin{tabular}{|c|c|c|c|c|}
\hline Rank & Medication & Exposure increase ${ }^{*}$ & Exposure in $2005^{*}$ & Exposure in $2010^{*}$ \\
\hline 1 & Poractant alpha & 32 & 32 & 63 \\
\hline 2 & Vitamin A & 13 & 8.3 & 21 \\
\hline 3 & Ibuprofen & 9.1 & 1.4 & 11 \\
\hline 4 & Fluconazole & 6.4 & 14 & 21 \\
\hline 5 & Piperacillin/tazobactam & 6.0 & 6.2 & 12 \\
\hline 6 & Lansoprazole & 5.7 & 9.8 & 16 \\
\hline 7 & Methadone & 4.9 & 3.1 & 8.0 \\
\hline 8 & Morphine & 4.8 & 49 & 54 \\
\hline 9 & Meropenem & 4.5 & 4.5 & 9.0 \\
\hline 10 & Nitric oxide & 3.7 & 8.9 & 13 \\
\hline 11 & Milrinone & 3.6 & 0.4 & 4.0 \\
\hline 12 & Cefepime & 3.2 & 4.6 & 7.8 \\
\hline 13 & Lorazepam & 3.0 & 23 & 26 \\
\hline 14 & Azithromycin & 2.9 & 0.1 & 3.0 \\
\hline 15 & Metronidazole & 2.9 & 8.4 & 11 \\
\hline 16 & Famotidine & 2.8 & 4.7 & 7.5 \\
\hline 17 & Acyclovir & 2.4 & 16 & 18 \\
\hline 18 & Cefazolin & 2.4 & 6.3 & 8.7 \\
\hline 19 & Sildenafil & 2.1 & 0.2 & 2.3 \\
\hline 20 & Linezolid & 2.0 & 0.4 & 2.4 \\
\hline
\end{tabular}


Table 5

Greatest relative decrease in exposure between 2005 and 2010 ( $\geq 1 / 1000$ infant exposures in 2005)

\begin{tabular}{|c|c|c|c|c|}
\hline Rank & Medication & $\%$ Change & Exposure $(2005)^{*}$ & Exposure (2010) ${ }^{*}$ \\
\hline 1 & Theophylline & -84 & 6.9 & 1.1 \\
\hline 2 & Metoclopramide & -84 & 88 & 14 \\
\hline 3 & Doxapram & -74 & 2.3 & 0.6 \\
\hline 4 & Aminophylline & -73 & 20 & 5.4 \\
\hline 5 & Epoietin alpha & -66 & 42 & 15 \\
\hline 6 & Imipenem+cilastatin & -63 & 4.8 & 1.8 \\
\hline 7 & Ranitidine & -61 & 80 & 31 \\
\hline 8 & Sodium polystyrene sulfonate & -61 & 3.1 & 1.2 \\
\hline 9 & Bethanechol & -59 & 2.2 & 0.9 \\
\hline 10 & Indomethacin & -58 & 61 & 26 \\
\hline 11 & Cefotaxime & -56 & 67 & 29 \\
\hline 12 & Amphotericin B products & -53 & 12 & 5.5 \\
\hline 13 & Ipratropium & -52 & 2.7 & 1.3 \\
\hline 14 & Ceftazidime & -51 & 17 & 8.5 \\
\hline 15 & Acetylcysteine & -47 & 1.7 & 0.9 \\
\hline 16 & Oxacillin & -46 & 12 & 6.4 \\
\hline 17 & Dobutamine & -46 & 26 & 14 \\
\hline 18 & Ceftriaxone & -46 & 2.4 & 1.3 \\
\hline 19 & Rifampin & -45 & 4.2 & 2.3 \\
\hline 20 & Palivizumab & -42 & 20.5 & 11.9 \\
\hline
\end{tabular}


Table 6

Greatest absolute decrease in exposure between 2005 and 2010

\begin{tabular}{|c|c|c|c|c|}
\hline Rank & Medication & Decrease in exposure * & Exposure in $2005^{*}$ & Exposure in $2010^{*}$ \\
\hline 1 & Metoclopramide & -74 & 88 & 14 \\
\hline 2 & Ranitidine & -49 & 80 & 31 \\
\hline 3 & Ampicillin & -39 & 699 & 659 \\
\hline 4 & Cefotaxime & -38 & 67 & 29 \\
\hline 5 & Indomethacin & -35 & 61 & 26 \\
\hline 6 & Epoietin alpha & -28 & 42 & 15 \\
\hline 7 & Beractant & -26 & 93 & 67 \\
\hline 8 & Gentamicin & -26 & 684 & 658 \\
\hline 9 & Dopamine & -23 & 73 & 50 \\
\hline 10 & Calfactant & -20 & 67 & 47 \\
\hline 11 & Vancomycin & -17 & 96 & 79 \\
\hline 12 & Furosemide & -16 & 89 & 73 \\
\hline 13 & Aminophylline & -15 & 20 & 5.4 \\
\hline 14 & Albuterol & -12 & 34 & 22 \\
\hline 15 & Dobutamine & -12 & 26 & 14 \\
\hline 16 & Midazolam & -9.3 & 63 & 54 \\
\hline 17 & Ceftazidime & -8.7 & 17 & 8.5 \\
\hline 18 & Palivizumab & -8.6 & 21 & 12 \\
\hline 19 & Spironolactone & -6.4 & 17 & 11 \\
\hline 20 & Amphotericin B products & -6.3 & 12 & 5.5 \\
\hline
\end{tabular}




\section{Table 7}

Greatest relative increase in exposure between 2005 and 2010 in ELBW infants ( $\geq 1 / 1000$ infant exposures in 2010)

\begin{tabular}{clccc}
\hline Rank & Medication & \% Change & Exposure (2005) & Exposure (2010) $^{*}$ \\
\hline 1 & Azithromycin & 2050 & 0.4 & 8.6 \\
\hline 2 & Ibuprofen & 1340 & 7.8 & 112 \\
\hline 3 & Sildenafil & 1125 & 1.6 & 20 \\
\hline 4 & Carnitine & 733 & 3.6 & 30 \\
\hline 5 & Cefuroxime & 700 & 0.2 & 1.6 \\
\hline 6 & Milrinone & 525 & 1.6 & 10 \\
\hline 7 & Linezolid & 464 & 3.1 & 4.3 \\
\hline 8 & Amlodipine & 291 & 1.1 & 3.7 \\
\hline 9 & Ganciclovir & 236 & 1.1 & 8.6 \\
\hline 10 & Cefoxitin & 219 & 2.7 & \\
\hline
\end{tabular}

*Per 1000 infants. 
Table 8

Greatest absolute increase in exposure between 2005 and 2010 in ELBW infants

\begin{tabular}{clccc}
\hline Rank & Medication & Exposure increase & Exposure in 2005 $^{*}$ & Exposure in 2010 $^{*}$ \\
\hline 1 & Vitamin A & 179 & 93 & 273 \\
\hline 2 & Caffeine citrate & 176 & 620 & 796 \\
\hline 3 & Poractant alpha & 135 & 100 & 235 \\
\hline 4 & Ibuprofen & 105 & 7.8 & 112 \\
\hline 5 & Fluconazole & 95 & 141 & 236 \\
\hline 6 & Gentamicin & 67 & 853 & 920 \\
\hline 7 & Fentanyl & 47 & 295 & 342 \\
\hline 8 & Meropenem & 45 & 36 & 81 \\
\hline 9 & Piperacillin/Tazobactam & 44 & 45 & 89 \\
\hline 10 & Lorazepam & 38 & 76 & 114 \\
\hline
\end{tabular}

Per 1000 infants. 
Table 9

Greatest relative decrease in exposure between 2005 and 2010 in ELBW infants ( $\geq 1 / 1000$ infant exposures in 2005)

\begin{tabular}{clccc}
\hline Rank & Medication & \% Change & Exposure (2005) & Exposure (2010) $^{*}$ \\
\hline 1 & Cromolyn & -93 & 2.7 & 0.2 \\
\hline 2 & Terbutaline & -88 & 3.4 & 0.4 \\
\hline 3 & Scopolamine & -87 & 4.5 & 0.6 \\
\hline 4 & Norepinephrine & -85 & 1.3 & 0.2 \\
\hline 5 & Metoclopramide & -79 & 298 & 62 \\
\hline 6 & Ceftizoxime & -75 & 1.6 & 0.4 \\
\hline 7 & Aztreonam & -74 & 3.8 & 1.0 \\
\hline 8 & Theophylline & -73 & 38 & 10 \\
\hline 9 & Doxapram & -70 & 22 & 6.7 \\
\hline 10 & Chlorpromazine & -69 & 1.3 & 0.4 \\
\hline
\end{tabular}

* Per 1000 infants. 
Table 10

Greatest absolute decrease in exposure between 2005 and 2010 in ELBW infants

\begin{tabular}{clccc}
\hline Rank & Medication & Decrease in exposure & Exposure in 2005* & Exposure in 2010 $^{*}$ \\
\hline 1 & Metoclopramide & -236 & 298 & 62 \\
\hline 2 & Ranitidine & -152 & 293 & 141 \\
\hline 3 & Epoietin alpha & -143 & 223 & 81 \\
\hline 4 & Indomethacin & -139 & 424 & 285 \\
\hline 5 & Cefotaxime & -118 & 282 & 164 \\
\hline 6 & Aminophylline & -64 & 94 & 30 \\
\hline 7 & Albuterol & -60 & 283 & 223 \\
\hline 8 & Dopamine & -57 & 449 & 392 \\
\hline 9 & Ceftazidime & -55 & 130 & 84 \\
\hline 10 & Dobutamine & -51 & 162 & 110 \\
\hline
\end{tabular}

* Per 1000 infants. 